\title{
Analysis on the Coordinated Development of Undergraduate Specialty Setting and Industrial Structure Optimization in Shaanxi Province
}

\author{
Fang Zhou ${ }^{1, \text { a }}$ \\ ${ }^{1}$ Business School, Xi'an Peihua University, Xi'an, Shaanxi, 710125 \\ a email
}

Keywords: Coordinate Development, Undergraduate Specialty Setting, Structure Optimization

\begin{abstract}
Knowledge economy era, science and technology and talent to become regional economic development, industrial structure upgrade a huge driving factor. Higher education as the training of talent and scientific research and innovation of the main positions, has increasingly become an important factor affecting the optimization and upgrading of industrial structure. As a result, the link between the professional structure and the industrial structure of higher education is becoming more and more close. Shaanxi Province, after nearly 10 years of rapid development of higher education, its rapid expansion of the scale. At the same time, its professional structure also appeared a lot of problems, such as the province of Shaanxi province professional structure appeared in the professional set of relatively concentrated phenomenon, the higher education professional structure area is not balanced, can not meet the specific requirements of regional economic development, Higher education outflow rate and so on. Therefore, it is necessary to study the optimization of higher education structure in Shaanxi Province.
\end{abstract}

\section{Introduction}

Since the year of China to carry out the national institutions of higher learning to adjust the work, the number of colleges and universities in Shaanxi Province by the founding of the year to the year, the number of its enrollment from the rapid increase from people. Since then established the status of higher education province of Shaanxi Province. As of the end of the year, Shaanxi Province has a total of institutions of higher learning, including ordinary institutions of higher learning, including subordinate institutions, provincial colleges and universities, provincial higher vocational institutions. The province of colleges and universities were enrolled in the general college students stare at more than 10,000 people, school students more than one person. In the same year, the number of graduate students in Shaanxi Province has reached 10,000, and the number of graduate students is more than that of the adult students. The number of students in the higher education is the fourth place in the country. However, it is not consistent with the year, Shaanxi Province is only ranked in the country seventeenth, higher education and economic development is clearly incompatible. In addition, the current co-existence with college students is difficult, the employing units are difficult to recruit the status quo, on the one hand some "hot" professional graduates employment is very difficult, on the other hand some tight professional or emerging professional graduates are in short supply, according to Shaanxi Province, the University of the recruitment of brochures, undergraduate professional set up the most professional English, computer science and technology, marketing, Chinese language and literature, art design, accounting and electronic letter project and so on. According to a survey of job seekers and job abilities of the University of China, these professions are more likely to be more likely to be employed or have a lower counterparty rate. Another data from the survey showed that the outflow rate of Shaanxi provincial university graduates was reached.

\section{Analysis of the Relationship between Professional Structure and Industrial Structure of Higher Education}

The optimization and upgrading of the industrial structure in the region will lead to the free flow of labor between the various industries, thus affecting and changing the employment structure and 
talent demand structure in this region. Because higher education is the main position of cultivating talents, so the change of talent demand structure will also affect the development of higher education, the objective requirements of higher education professional structure adjustment and change to adapt to changes in industrial structure of the new demand for talent. In addition, the optimization and upgrading of industrial structure requires scientific and technological innovation to promote, scientific and technological innovation is mainly dependent on innovative talents and technology, all this has a great connection with higher education, because a basic function of higher education is to cultivate talent and science the study. Therefore, the higher education and economic development are inextricably linked, the professional structure of higher education and the optimization and upgrading of industrial structure are also closely related to the adjustment of the structure of higher education to promote the development of industrial structure.

Higher education structure refers to the proportion of the elements of the higher education system and the relationship between the way, is a multi-level multi-dimensional complex structure of the complex. The structure of higher education mainly includes the macro structure of higher education and the microstructure of higher education. The macro structure of higher education refers to the structure of higher education, which is closely related to external factors such as economy and social development. It mainly includes hierarchical structure, scientific structure, formal structure, distribution structure and management structure. The microstructure of higher education mainly includes the professional structure and curriculum structure, the organizational structure and the teacher structure of the university. Reasonable educational structure should be able to adapt to the social and economic development of the demand for talent, and not contrary to the development of their own laws of education dynamic balance. This kind of education system should be conducive to the rational allocation of educational resources, is conducive to the full development and use of the education system of human, material and financial resources, to achieve the best benefits. However, it is not enough to pay attention only to the adaptability of the educational structure to socio-economic development. We also need to strengthen our attention to our resilience. We should pay attention to the flexibility of the system construction in the process of adjusting and optimizing the structure of higher education. We can not just look at the present. Professional structure refers to the type of professional and the combination of professional spear. The professional structure is an important aspect of the structure of higher education. Professional structure from two aspects to understand, one is a variety of professional elements, the other is the relationship between different professions. Professional factors include a professional connotation, quality and caliber, etc., the relationship between the professional, including the number of different professional, layout, proportion, size and the relationship between each other. The professional structure optimization referred to in this paper mainly refers to the optimization and adjustment of the latter. Professional structure optimization, refers to the increase or decrease the number of various professional, adjust the proportion between the professional structure and integration of professional categories of methods to change the original professional structure, and to improve the original content of some of the professional and caliber, To meet the needs of the socio-economic needs of the process of talent. Of course, the professional structure is fully adapted to the socio-economic needs of the situation is not really there, so we mentioned the optimization of the professional structure refers to a professional structure and socio-economic needs of a relatively balanced state. Its ultimate goal is to adapt to the economic and social needs of professionals change.

\section{Analysis of the Current Structure and Industrial Structure of Higher Education in Shaanxi Province}

Before the reform and opening up, Shaanxi Province as a national talent training base, its higher education is mainly for the country. After the reform and opening up, the development of higher education in Shaanxi Province has been in the national leading position, but because of historical and economic reasons, Shaanxi Province, the phenomenon of brain drain has been very serious. According to the talented outflow data of the provinces in the provinces and universities, the 
outflow rate of Shaanxi provincial university graduates has reached the top of the country.

Shaanxi Province, the modern industrial structure, is gradually developed after the founding of the country. In the period of the "fifteen" and "second five" construction periods, Shaanxi Province became the key area of China's construction in the Mainland. During the 15th period, the country had a total of key projects, among which there was a layout in Shaanxi, forming a large number of industrial agglomeration Area, laid the industrial base of Shaanxi. Which is representative of the western suburbs of Xi'an Electrician City, the eastern outskirts of the military city and textile city, Yanliang aircraft city, Baoji ginger city and so on. But we can see that these industrial clusters are mostly in the central area of Xi'an. Which is also a direct result of the current industrial structure of Shaanxi Province, a serious imbalance. "Three lines" construction period, Shaanxi Province has once again become one of the key areas of national construction, many industries such as aerospace, electronics, machine equipment, heavy vehicles, nonferrous metals and other areas of coastal enterprises have moved to Shaanxi. The development of these enterprises has become the pillar of Shaanxi modern industry. In short, in the period of "one five", "second five" and "three lines" construction, Shaanxi Province gradually formed a relatively complete industrial system, especially in Xi'an as the center of Guanzhong region, became the economic center of the Northwest, Has also become one of China's industrial base.

\section{Suggestions on the Adjustment of Undergraduate Specialty Structure in Shaanxi Province}

In the next period of time, the province of higher education, to strengthen the engineering, science, medicine and other large demand for professional construction, slowing literature, management, education and other professional development and focus on these specialties To carry out connotation construction, adjust its internal structure. Another need to put forward is that the rapid development of modern agriculture requires more advanced knowledge of agricultural talent, so we want to strengthen the team of agricultural construction and investment. Shaanxi Province is also currently has two undergraduate institutions Shangluo College and Ankang College. The area as a new green agricultural base, there is great prospects for development. Properly strengthening the construction and investment of agronomy will provide a great impetus to the economic development of the region. Guanzhong region is the most concentrated and high-level university in Shaanxi province and even the whole northwest region. As the most economically developed areas in Shaanxi Province, there are not only advanced manufacturing industries, but also the rapid development of the tertiary industry and high-tech industries. Therefore, Guanzhong colleges and universities not only to strengthen the engineering, science and medical and other professional personnel training, but also to attach importance to emerging professionals and high-tech talent training. In addition, many colleges and universities in this region have a strong scientific research and teaching strength, through cooperation and exchange to help the northern Shaanxi and southern Shaanxi colleges and universities to promote the construction of colleges and universities in Shaanxi Province to further optimize the professional structure.

The connotation and quality of subject specialty are the key factors that colleges and universities can cultivate talents to meet the needs of social reality. At present, the employment pressure of college graduates is getting bigger and bigger. The demand of talents is increasing. And the adaptation of the economic structure. Therefore, the provincial colleges and universities must strengthen the connotation of the construction of disciplines, focusing on promoting the construction of professional characteristics and comprehensive development, to enhance the overall level of professionals to improve the quality of graduates to improve the knowledge structure of graduates to enhance the graduates Social adaptability, in order to enhance the competitiveness of colleges and universities.

Strengthen the integration of professional development of disciplines, and enhance the flexibility of disciplines. The development of modern economy, more and more need to integrate the talent. China's professional development of higher education has been a professional division is too small, caliber too narrow ills, so the provincial university professional construction must pay attention to the professional development of disciplines. First of all, colleges and universities should take 
measures to promote the integration of liberal arts and science and engineering, through the reform of elective courses to strengthen the cross-disciplinary professional cross. Strengthening the Humanities' Knowledge and Knowledge of Science Students by Strengthening the Learning of Humanities and Cultivating New Type of Liberal Arts through Curriculum Integration. Second, actively set up a comprehensive, interdisciplinary professional courses, broaden the professional caliber, deepen the professional knowledge of students, so that students' knowledge structure and capacity structure to adapt to changing social needs. Finally, increase the flexibility of the course system. Through the flexibility to change the curriculum system to increase the discipline of professional demand for social adaptability, so that professional education and market demand more closely. The main approach is to focus on the basic course of students, to break the previous professional barriers to promote the discipline between the professional knowledge and communication, increase the adaptability of the curriculum, but also increase the professional adaptability.

\section{Conclusion}

Shaanxi Province, higher education due to historical reasons, and the region's economic development has been in an unbalanced state, the development of relatively advanced. How to make Shaanxi higher education to better serve the regional socio-economic development, to achieve sustainable development is an imminent problem. However, the development of anything is a process from quantitative to qualitative change. At present, the optimization of the professional structure of higher education in Shaanxi Province needs to be implemented in a planned way. In this process, we have to make good use of Shaanxi Province, higher education itself is more developed this favorable conditions, play an advantage, make up for deficiencies.

\section{Acknowledgements}

Fund Project: Tourism Science Planning Project of Shaanxi Province in 2017: Optimization of Industrial Structure and Optimization of Undergraduate Specialty Setting in Shaanxi Province (SGH17H455)

\section{References}

[1] Pei Chengrong. Path selection of Shaanxi industrial structure optimization and upgrading [J]. Shaanxi Development and Reform. 2010 (03)

[2] Yu Junlin. Jiangxi University of professional structure and local economic structure docking status and strategy research [J].Journal of Jiangxi Agricultural University. 2009 (03)

[3] Yao Conglie. Education and Economic Perspective: An Analysis of "Shaanxi Phenomenon" [J]. Journal of Northwest University, 2009 (02)

[4] Liu Dianhui, Liu Jia. Journal of Changchun University of Technology (Higher Education Study Edition). 2008 (04) (in Chinese with English abstract)

[5] Zheng Fengying. Construction of Undergraduate Structure of Science and Engineering in Local Normal University. 2008 (06)

[6] Wang Li. Shaanxi University and regional economic development coordination analysis [J].Journal of Northwest A \& F University (2008) 